\title{
CUERPOS DESGARRADOS: TEXTUALIDADES DESGARRADORAS. UNA APROXIMACIÓN A LA ESCRITURA DE CLAUDIA HERNÁNDEZ
}

\author{
Carla Rodríguez Corrales
}

\begin{abstract}
RESUMEN
La producción literaria centroamericana contemporánea constituye un espacio para la (des) configuración identitaria de los sujetos y el desmoronamiento de los grandes discursos imaginarioculturales. Dicha premisa exige la búsqueda y la resignificación constantes. Por esta razón, el siguiente trabajo se centra en el estudio del cuentario De fronteras (2007) de la escritora salvadoreña Claudia Hernández. La lectura de dicha propuesta permite aproximarse a los modos de (des)construcción de los cuerpos-sujetos que habitan tanto las textualidades culturales como las literarias y -como contrapunto- posibilita la (des)articulación de los textos culturales e imaginarios en esos cuerpos-sujetos. Hablaremos, por tanto, de cuerpos textuales, de grafías fragmentadas, de grietas corpóreas que entran en tensión al intentar 'ser', 'habitarse': 'decirse'.

Palabras clave: Literatura centroamericana, identidad, sujeto, cuerpo, Hernández-Claudia.
\end{abstract}

\begin{abstract}
The contemporary American literary production constitutes a space for the subjects identity (des) configuration and the collapse of the cultural-imaginary speech. This premise requires search and constant re-signifying. For this reason, the following work focuses on the study of the 'cuentario' De fronteras (2007) of the salvadoran writer Claudia Hernández. The reading of this proposal allows approaching to the body-subjects (des)construction types that live both the literary and cultural textualities and - as a counterpoint - enables the body-subjects (des) articulation of the imaginary and cultural texts. Therefore, we'll talk about textual bodies, fragmented spellings, corporeal cracks that can become stressed when trying to 'be', 'live': 'say'.

Keywords: Central American literature, identity, subject and body, Hernández-Claudia.
\end{abstract}

La memoria es un músculo raro. Se mueve solo. Cuando nadie lo espera

Julio Cortázar

[La poesía esa] realización de un cuerpo que se constituye como enemigo y desde allí nos mira. Pero cada paso dentro de esa enemistad provoca estela o comunicación inefable

Claudio Vitier

ML. Carla Rodríguez Corrales. Profesora de la Escuela de Filología, Lingüística y Literatura. Universidad de Costa Rica.

Correo electrónico: caroco_82@yahoo.com

Recepción: 05- 11- 2012

Aceptación: 28- 11- 2012 


\section{Preámbulo}

Sin duda alguna, la producción literaria centroamericana contemporánea ha ido trazándose desde distintos caminos a partir de los cuales ha ido delineando una silueta poliforme de sus propias realidades. Pese a esa multiplicidad, el tronco común de sus letras ha sido -ineludiblemente- la interrogación y la búsqueda de la identidad. Los motivos que impulsan a seguir dicha búsqueda podrían, quizás, originarse en el pasado colonial, reafirmarse con el neocolonialismo, las guerras civiles, la incompletud del proyecto de la modernidad y las actuales exigencias del aplastante proceso globalizador. Lo cierto del caso es que si la producción textual centroamericana responde a uno, a dos o a todos estos hechos, esto lo único que evidencia es la necesidad permanente de autodefinición. Actitud que no es exclusivamente centroamericana, pues se comparte con todos aquellos pueblos que fueron explotados y dominados por otra nación considerada "superior". Se trata de una posición discursiva e ideológica que coloca a unos pueblos/sujetos por debajo de 'otros'. Es un rol heredado, interiorizado, encarnado. Al ser una condición casi fosilizada, salir de ella resulta bizarro y como lo vemos en nuestras realidades y en la Literatura: inacabado.

Ahora bien, la insistencia en dicha temática podría conducir a algunos a considerar los textos literarios centroamericanos como unísonos, monótonos, repetitivos. ¿Por qué hablar de identidad?, ¿para qué hablar de identidad si no existe una identidad como tal? Estos cuestionamientos serían válidos, pero limitados. Equivaldría a ignorar que existe una relación muy estrecha entre la producción textual y las realidades, entre la Literatura y la memoria, entre los textos y los sujetos. Sería olvidar que la Literatura es un espacio para (re) inventarse, para (des) construir, para (des) decir-nos, o bien, como afirma el escritor uruguayo Eduardo Galeano en relación con la utopía, para caminar. ${ }^{1}$

Esto significa que la literatura centroamericana emprende a cada instante la búsqueda incesante de más modos desde dónde ser, sin detenerse a considerar si esto es posible o no. Tal parece que esto carece de importancia. Esta cualidad de la Literatura denota cierta despreocupación por el hallazgo en sí, el afán de la búsqueda no reside en el encuentro de un objeto o un concepto (la identidad); sino en el proceso, en el camino. En lo que se logre en el intento de acercarse a eso que ya -de por sí- se sabe es: inalcanzable. De allí la pertinencia de la homologación que antes establecí entre utopía y Literatura.

Lo anterior demuestra que la realidad no es capaz de ofrecer esos espacios que sí brinda a manos llenas la textualidad, aunque sea tan solo en el espacio que separa a una letra de otra, a una imagen de otra. Un momento que procura sobrevivir al proceso de la lectura (re-escritura) que realizamos cada uno de nosotros.

En vista de las particularidades que rodean la Literatura centroamericana, el reto y el compromiso de cada uno de nosotros como lectores radica en hallar y desentrañar de qué modo las imágenes textuales (des) construyen la identidad de los sujetos y cómo con ello se desmoronan los grandes discursos imaginario-culturales. En respuesta a lo anterior, en esta oportunidad, le prestaremos especial atención a la propuesta literaria de la escritora salvadoreña Claudia Hernández $(1975)^{2}$ en su obra De fronteras publicada en el 2007. El análisis se centrará específicamente en los cuentos: "Abuelo", "Manual del hijo muerto" y "Mediodía de frontera".

\section{2. ¿Un cinismo desencantado o un desencanto cínico?}

Como parte de la tarea revisionista que exigen el acercamiento y el análisis de la producción textual de Claudia Hernández, hallaremos que la historiografía y la crítica 
literarias han ubicado su trabajo como parte, o más bien, como exponente de la "generación" de los 'posmodernos desencantados'; por lo tanto, convendría esclarecer esta etiqueta.

Dicha denominación ha recibido otros nombres: "novela urbana", "nueva narrativa centroamericana", "ficción contemporánea centroamericana", "literatura de posguerra". También se ha conocido con el nombre de 'realismo sucio' que supone la apertura a la influencia del lenguaje cinematográfico y al discurso homogenizador de los medios masivos. En todos estos casos, su definición no resulta aplicable a las producciones literarias de otras geografías, pues se trata de una manifestación gestada en / desde las letras centroamericanas ${ }^{3}$.

Así, la crisis política y económica vivida a partir de 1950 fue un fenómeno que marcó las realidades centroamericanas. La guerra civil en El Salvador y en Guatemala, y el sandinismo en Nicaragua, afectó directa y profundamente el status quo de la región. Tras estos procesos, la posguerra colocó a Centroamérica frente a la ruptura de la identidad idealizada (la perfecta 'antiutopía'). Este nuevo panorama sugiere el replanteamiento de las estructuras nacionalistas y la reformulación de nuevos imaginarios. Sumado a ello, se desata la resistencia frente a la globalización. Así, al finalizar el siglo XX, sobreviene el fracaso de las utopías revolucionarias y el pesimismo existencial. Este malestar colectivo se asocia a los signos de la denominada posmodernidad y por ende a:

\footnotetext{
La disolución de la categoría clásica de sujeto, el fin de los grandes relatos, la crisis de los sistemas explicativos apegados a un principio unitario y sustentadores de jerarquías. Esto tiene su obvia contraparte en la puesta en cuestión de dos claves fundamentales de la modernidad: la identidad y la representación. (Núñez 1997)
}

Justamente, Beatriz Cortez en su artículo denominado "Estética del cinismo: la ficción centroamericana de posguerra" (2000) alude a la reinvención de las producciones culturales de Centroamérica, específicamente, la ficción contemporánea. De acuerdo con su planteamiento, durante el período de lucha armada, la literatura estuvo ligada a las revoluciones a través de las producciones testimoniales, lo cual le concedió un sitio secundario a la ficción. Sin embargo, el panorama cambia al finalizar las guerras civiles ${ }^{4}$, pues diversas temáticas, al margen del proyecto revolucionario, adquieren espacio dentro de la textualidad.

Vinculada a esta última idea, Cortez establece una filiación entre las propuestas de la literatura contemporánea y la denominada literatura testimonial ${ }^{5}$. Ambas producciones concuerdan en resquebrajar las versiones oficiales desde las cuales se construye la identidad centroamericana; de este modo, ambas tendencias desmitifican los discursos y adquieren un tono desesperanzado.

En realidad, resultaría ilusorio suponer que la literatura testimonial y la ficción se contraponen, ya que no es así; ambas denuncian la inexactitud de las versiones oficiales de identidad centroamericana. Quizás este es el elemento primordial, dado que a partir de él se articula toda la producción centroamericana de posguerra.

Ante la utopía agonizante, la posguerra pretende sopesar los patrones anteriores y reemplazar el testimonio por la búsqueda de posibilidades de expresión y representación. No pretende esclarecer y mucho menos hallar una verdad irrefutable; sino una posición múltiple, donde la voz no provenga de un centro, sino de las experiencias íntimas de los sujetos, donde emergen las más férreas revelaciones de las voces esquizofrénicas y paranoicas. Prefiere internarse en la duda y las subjetividades. Es, precisamente, desde las representaciones de la intimidad que se exploran las pasiones y se tejen las identidades. Es el sitio donde las formas se fragmentan y los sujetos entran en crisis, de allí que sea un lugar para perderse. 
En medio de los trazos desdibujados, se comienza a delinear la literatura contemporánea. En este proyecto participan autores como Salvador Canjura, Jacinta Escudos, Manlio Argueta, Claudia Hernández y Rafael Menjívar Ochoa (salvadoreños); Horacio Castellanos (hondureño-salvadoreño) ${ }^{6}$; Roberto Quesada (hondureño); Rodrigo Rey Rosa, Mario Alberto Carrera, Mario Roberto Morales y Francisco Méndez (guatemaltecos); Erick Aguirre y Franz Gallich (nicaragüenses); Rodrigo Soto, Alexander Obando, Sergio Muñoz y Carlos Cortés (costarricenses) ${ }^{7}$ (Cortez 2000: 2).

Todos ellos poseen una estética particular, no obstante, comparten la preocupación por una realidad quebradiza, y este aspecto es tal vez, el que más los identifica con la crítica al proyecto de la modernidad. Además, no resulta fortuito que sus textos presenten como escenario la ciudad, cuyas imágenes plasman la oquedad del medio y "los deseos más oscuros del individuo, sus pasiones, su desencanto [...] y su interacción con un mundo de violencia y caos" (Cortez 2000: 1).

Como parte de este proceso sobreviene el cuestionamiento de los discursos unitarios que anhelan fosilizar la representación de la realidad, en consecuencia, al sujeto solo le resta flotar en medio de signos que se mueven sin cobrar significado. En medio de la desarticulación de los principales paradigmas, solo se cuenta con las piezas borrosas de un rompecabezas, partes dispersas de realidades y de sujetos que "han dejado de creer en utopías y asumen la frustración y la derrota como vivencias más auténticas" (Vásquez 2002: 35).

Ahora bien, esta tendencia será denominada por algunos estudiosos como "estética del cinismo". Beatriz Cortez apunta que esta se convierte en una estética en la medida en que representa una posibilidad de expresión del sujeto desencantado, una "estrategia de sobreviviencia del individuo en un contexto social minado por el legado de la violencia de la guerra y por la pérdida de una forma concreta de liderazgo" (Cortez 2000: 4). Quizás, un modo de enfrentar la disolución de las formas, un mecanismo o filosofía de vida, o más bien, de sobrevivencia. Una manera de explorar la intimidad, de construir subjetividades y de "teorizar con respecto a la fragmentación de la identidad que caracteriza a la posmodernidad" (Cortez: 2000: 2). Así lo reafirma Hugo Sánchez (2011) en su artículo "Generación del cinismo y la desesperanza", siguiendo las palabras de Mauricio Aguilar Ciciliano:

\footnotetext{
Entendemos por estética del cinismo una propuesta de ficción narrativa donde los personajes, vacíos de todo contenido ideológico y social, desprecian el sistema de normas y creencias limitándose a desbordar sus pasiones donde encuentran alguna manera de sobrevivir. Se reafirman en la intimidad, el erotismo, la violencia y la fuga topográfica para salvarse de la nada. (Aguilar, citado en Sánchez 2011)
}

Específicamente, en el caso de la sociedad salvadoreña, el "cinismo" obedece al fracaso de dos modelos que han vivido en lucha durante mucho tiempo en el país y que han producido una profunda crisis de identidad. Estos son: el proyecto revolucionario de izquierda, en su visión original, que prometía la construcción de un nuevo sujeto (el sujeto revolucionario) y el modelo mercantilista y globalizante que exige, no una sociedad de valores, sino una sociedad de consumo.

Estamos ante un proyecto teñido por la desesperanza y la caída de las utopías. De allí, la recurrencia a espacios donde prevalecen la corrupción, la violencia y la crisis existencial de los sujetos, representados por la incomunicación, la orfandad y el absurdo. Tal y como lo manifiesta Mauricio Aguilar Ciciliano, referido en el artículo de Hugo Sánchez, la violencia constituye un legado para las sociedades centroamericanas: 
Encontramos en buena parte de la narrativa salvadoreña actual una correspondencia interesante con el imaginario social de violencia de nuestro país. Hay, pues, una nueva tendencia estética predominante [...] como recurso de desvelamiento de la falsa conciencia nacional fundada en valores que sólo han llevado a la degradación mayor del sujeto. (Aguilar, citado en Sánchez 2011)

De forma similar, para Edelberto Torres-Rivas la violencia es una constante que marca y recorre las venas del territorio centroamericano, por lo tanto, cualquier producción social y artística estará impregnada -en cierta medida- de ella. En congruencia con esto, la poetisa salvadoreña Silvia Elena Regalado explica que los escritores del "cinismo" escogen una manera seca, dura y violenta para crear sus realidades, con el propósito de sacudir y hacer despertar a los lectores acerca de sus propias realidades. Se trata, en palabras del poeta salvadoreño Alberto López Serrano, de "plasmar situaciones muy grotescas de formas que son muy irónicas o muy exageradas a veces [...] Es como mofarse de un hecho grave o malo, por así decirlo, pero es también para llevar a una reflexión” (Torres-Rivas 1994: 195). Al fin y al cabo, como menciona Regalado, ninguna expresión literaria esta ajena a su tiempo ni a la sociedad en que vive.

\begin{abstract}
Aunque la cultura de la violencia y de miedo no es exclusiva de la década de los ochenta, sí lo es su carácter más profundo y generalizado. Sus secuelas ya pueden observarse en El Salvador y Guatemala en la forma de autocensura, hábitos de retraimiento e intolerancia y cultivo de actitudes autoritarias, la prepotencia de las armas y la violencia derivadas de la experiencia cotidiana de la guerra y de la muerte. (Torres-Rivas 1994: 195)
\end{abstract}

Sumado a lo anterior, la ficción centroamericana de posguerra trabaja las subjetividades y se ubica en la intimidad, en el resquicio de lo cotidiano, es allí donde el individuo se autodestruye para luego re-construirse. Donde aflora la pérdida de la fe en los valores morales y en los proyectos sociales de carácter utópico, donde todo concepto pierde universalidad porque nada es absoluto. Por tanto, en el espacio textual se proponen nuevas formas de concebir(se), y esto se asocia directamente con las teorizaciones posmodernas acerca de la naturaleza fragmentaria e híbrida de la subjetividad donde todo es desencantado, cínico.

La ficción centroamericana de posguerra presenta a un individuo sometido a las normas sociales que rigen el espacio público [y que está] forzado a representar las versiones oficiales y hegemónicas de la identidad centroamericana [...] Sin embargo, hay un espacio público en el que el individuo se puede mostrar tal cual es y romper con las normas establecidas por la decencia y la buena reputación en estas ciudades, donde las versiones oficiales de la identidad se pueden poner en duda, donde la decencia y la buena reputación se muestran como simples máscaras y donde el individuo puede transgredir identidades y experimentar con placeres vedados. Ese lugar es la ficción contemporánea. (Cortez 2000: 20)

\title{
3. El cinismo y el desencanto desde el marco de lo 'pos-'
}

Ahora bien, conviene subrayar que tanto la categorización como el estudio de la Literatura centroamericana contemporánea se gestan desde el marco de la llamada posmodernidad, -término nada fácil de ubicar dentro de las latitudes del istmo-, por lo cual será necesario detenerse a discutir algunos de sus elementos constitutivos y establecer una relación con la configuración de los sujetos, sus cuerpos y sus identidades.

Partiremos de que la posmodernidad es el período histórico contemporáneo que impone, a su vez, un estilo de pensamiento y de vida. Se caracteriza por la desconfianza hacia las nociones de 'verdad' e 'identidad' vinculadas con los grandes relatos; de allí que opte por considerar al mundo como contingente e inexplicado. Entonces, suponer que el 'nuevo' 
capitalismo, unido al consumismo y a la industria científico-tecnológica, actúa en forma independiente, resultaría absurdo.

De hecho, Scott Lash (1990) afirma que el posmodernismo se vincula directamente con la (des)organización de la economía y las sociedades capitalistas. Por consiguiente, la recepción de la cultura posmodernista se asocia no sólo con una nueva forma de vida, sino también, con un espacio descentrado, con fronteras casi inexistentes. Esto nos remite ya a la indeterminación de la identidad social como consecuencia de la coacción de los mercados simbólicos, la expansión de las políticas capitalistas y la masificación.

Dadas estas características, el posmodernismo vendría a constituir un fenómeno cultural, un régimen de significación, cuyo rasgo fundamental, en contraposición con la modernidad, es la des-diferenciación. Por este motivo, las situaciones por las cuales atraviesan los individuos estarán claramente marcadas por el relativismo, pues no hay certeza de nada. Los sujetos posmodernos viven en el vacío,

\footnotetext{
ligad[o]s a sensibilidades [...] nuevas: de temporalidades menos "largas", más precarias, dotadas de una gran plasticidad para amalgamar ingredientes que provienen de mundos culturales muy diversos, y por lo tanto atravesadas por discontinuidades en las que conviven gestos atávicos, residuos modernistas y vacíos postmodernos. Esas nuevas sensibilidades [se] conectan con los movimientos de la globalización tecnológica que están disminuyendo la importancia de lo territorial y de los referentes tradicionales de identidad. (Barbero 2003: 30)
}

Las premisas posmodernistas cuestionan la realidad porque está conformada por imágenes y representaciones. Por lo tanto, la des-diferenciación posmodernista coloca el caos y la inestabilidad en la experiencia de la realidad. Así, la problemática reside en lo que percibimos en la televisión, en la difusión de la tecnología de la información, en los avisos publicitarios, pues todas son representaciones e imágenes. Justamente, la teórica Agnes Heller (1989) apunta que el nuevo estadio histórico posterior a la modernidad, disuelve la categoría de lo nuevo y difunde la experiencia de la ahistoricidad en la imagen televisiva, en la escritura y en la cultura del espectáculo. Es decir, la realidad histórica desaparece y emerge el simulacro.

Lo anterior, concuerda con la propuesta de Anthony Giddens (1995), para quien la reorganización del tiempo y del espacio que supone la modernidad transforman de modo inevitable la percepción del mundo/realidad cotidiana. Así, cuando las nociones de tiempo y espacio se vuelven múltiples generan en los sujetos nuevas formas de apropiación de las realidades.

Con la globalización, la vida diaria se reinstaura en función de la interrelación entre lo local y lo universal, los individuos se ven forzados a elegir estilos de vida entre la diversidad de opciones. Este fenómeno influye/determina -a su vez- la transformación de la intimidad de los sujetos. La duda se convierte en un rasgo que penetra en el mundo contemporáneo, de allí que las relaciones entre los sujetos estén mediatizadas por una "coraza" que protege al individuo de los 'otros'.

Estas condiciones se homologan a "la pérdida de la noción de proyecto social global, abandono de la voluntad, narcisismo autocentrado, [...] eclipse del sentido [que conduce] hacia la indiferencia o la autodestrucción" (Follari 1994: 16). Factores que arrastran a los llamados 'sujetos posmodernos' a la desesperanza, el individualismo y la indiferencia ante cualquier otra realidad que no sea la personal.

Quizás, debido a lo anterior, para la posmodernidad el cuerpo es una de sus grandes preocupaciones, ya que ofrece un grado de conocimiento íntimo. En sí, el cuerpo adquiere 
relevancia en este discurso porque es concebido como el centro desde donde se organizan y cobran sentido los sistemas significantes. Cuando el cuerpo interactúa con el lenguaje, hablaremos del sujeto.

Giddens se refiere a la identidad de los sujetos y sostiene que un individuo necesita, en primer lugar, conocer (se), es decir, poseer una conciencia práctica, contarse desde la experiencia. La realidad es captada desde la práctica, aquí es donde el cuerpo adquiere vital importancia, pues este conecta la realidad interna con la externa, "es un lugar fronterizo entre el adentro y el afuera" (Torras 2007: 15). Así, la captación/vivencia de los sentidos está circunscrita al marco social (al mundo externo) y a la experimentación de las nociones de tiempo-espacio; dicha interacción constituirá la "realidad" de ese sujeto.

De este modo, en el cuerpo recae la función de integrar ambas dimensiones de la realidad subjetiva: el afuera y el adentro. Nótese aquí que el cuerpo es concebido como una entidad articulada, capaz de conferirle existencia/presencia concreta al sujeto frente a los 'otros'; por ello, la disociación corporal del individuo se homologaría a una crisis en la configuración identitaria.

Conviene aclarar que el conocimiento de la "realidad" no nace únicamente de la percepción, sino - más bien- de las diferencias establecidas en la vida diaria, en otras palabras, "de la experiencia mediada" (Giddens 1995: 60). Es decir, "la intersubjetividad no se deriva de la subjetividad, sino al contrario” (Giddens 1995: 70). El descubrimiento de los 'otros' resulta vital para la existencia del sujeto. Sin 'otros' no hay 'yo'.

Así, la identidad del "yo" no es simplemente la suma de las continuidades de la acción individual, sino una noción que deberá ser creada y mantenida a cada momento por del individuo. En este caso, la identidad vendría a constituir continuidad en el tiempo y en el espacio. Siguiendo esta premisa, resultaría equívoco afirmar que la identidad subjetiva deviene únicamente del comportamiento del sujeto o de las reacciones de los 'otros' ante éste, en realidad, conforma una noción que delinea la idea de cómo se ha percibido ese cuerpo-sujeto en otros tiempos y espacios.

$\mathrm{Y}$ es que no se debe perder de vista que el cuerpo es la representación material del sujeto, el lugar para la identidad, entendida ésta como la articulación de género, raza, clase e identidad sexual. El cuerpo es el texto que resulta de la inscripción y la reinscripción de los discursos culturales. Por ello,

\footnotetext{
para ser reconocido como cuerpo humano no basta con ser un organismo biológico y funcional [...] Los cuerpos se constituyen como una suerte de metáforas de la sociedad a la que pertenecen. Existe un reconocimiento ligado a la modelación y al disciplinamiento sobre los cuerpos y sus actuaciones sociales, que los esculpe y los jerarquiza en función de un cuerpo ideal para cada identidad establecida: hombre, mujer, rico, pobre, blanco, negro... El cuerpo es fronterizo, se relaciona bidireccionalmente con el entorno sociocultural; lo constituye pero a la vez es constituido por él. (Torras 2007: 21)
}

Es por esto que los sujetos siempre estarán atados al discurso, siempre buscarán ser dichos, tener historia, contarse. Los cuerpos son objeto y sujeto del lenguaje, existen por y para él. Los cuerpos son textos. "Objetos materiales, y si no lo fueran no podría haber relación entre ellos” (Eagleton 1997: 116).

\footnotetext{
Nuestros cuerpos, en consecuencia, devienen visibles y actantes bajo el control y la vigilancia de las instituciones que, desde flancos diversos y cruzados, mantienen normalizados a los sujetos-cuerpos. Este control tiene lugar en el mismo proceso de ser cuerpo o sujeto, por lo que no es discernible ni extrapolable de nuestra propia subjetividad-materialidad. (Torras 2007: 21)
} 
Por ello, el cuerpo no podrá ser pensado como una materialidad previa e informe, ajena a la cultura. El cuerpo cobra una existencia performativa dentro de los marcos culturales que lo hacen visible. Siendo así, no cabe la menor duda de que "el cuerpo dice quiénes somos. Nos escribimos en el cuerpo y, a la vez, el cuerpo nos escribe" (Torras 2007: 17-18). Esta premisa es justamente la que motiva el acercamiento a la escritura de Claudia Hernández y la búsqueda de los modos en los cuales se (des) configuran los cuerpos dentro de sus textos. ¿Qué dice nuestro cuerpo de nosotros (as)?, ¿Qué potestad o control tenemos sobre su relato?, ¿De qué o de quién depende? Esas serán algunas de las interrogantes que intentaremos dilucidar a continuación.

\title{
4. Cuando se desgarran los cuerpos
}

"Abuelo" es el título de uno de los cuentos pertenecientes al texto de Claudia Hernández De fronteras. La razón por la cual está incluido en este estudio gira en torno al tratamiento de la muerte, la violencia y la corporeidad. Desde una mirada singular e irónica, la diégesis relata cómo los personajes del mundo narrado enfrentan la muerte de un ser querido: el abuelo. En el afán de superar el dolor que esto representa, el narrador-protagonista descubre que el cuerpo constituye el objeto (masa) donde reside la vida o la muerte. Por lo tanto, el cuerpo es el único elemento tangible que se posee para comprobar/asegurar la existencia o la inexistencia de un ser/sujeto (de ahí la agónica pesadumbre que sufren los familiares que no hallan el cuerpo de un ser querido para sepultarlo).

Si bien, el narrador-protagonista (quien no posee nombre) reconoce que humanamente le resulta imposible resucitar al abuelo, metafóricamente es viable "tenerlo de vuelta": ¿cómo?, pues trayendo del cementerio el cuerpo del abuelo. Sí, eso es justamente lo que ocurre. El narrador-protagonista excava la fosa del abuelo, extrae su osamenta y lo lleva a su casa; no sin antes, haber negociado con el encargado del cementerio regresar el cadáver el lunes siguiente.

\begin{abstract}
Fue idea mía. Se me ocurrió porque echaba de menos al abuelo. Aunque habían trascurrido ya dos años con tres meses desde su entierro, aún no podía acostumbrarme a su ausencia [...] No podía. Lo había intentado -de verdad-, pero no conseguía habituarme a estar sin él. Por eso, un jueves por la tarde, decidí ir a buscarlo, a la hora del almuerzo, sin ayuda. Me fui al cementerio a buscarlo para llevarlo de nuevo a casa. (Hernández 2007: 57)
\end{abstract}

Una vez que el cuerpo del abuelo está de nuevo en casa, el narrador convoca a toda su familia a una reunión en la cual la sorpresa será el abuelo. Los familiares acuden al llamado y, al ver al abuelo, creen que es una visión producto de su intento por recordarlo. Sin embargo, pronto descubren que en verdad el abuelo está de nuevo entre ellos, lo besan, lo abrazan, le hablan:

\footnotetext{
No hubo quien no quisiera tocarlo. Se lanzaban a besarlo y a contarle los últimos sucesos de la familia. Los nietos no cesaban de saltar a su alrededor y los hijos de paraban de tocarse el pecho y luego tocarlo a él diciendo "no puede ser, no puede ser". La abuela estaba transformada. Brillaba. Se había colocado bajo los brazos de él y me agradecía por haberlo llevado de vuelta. (Hernández 2007: 59)
}

Ante la emoción y la algarabía de "tener prestado" el cadáver del abuelo, el protagonista decide no privar a su familia de tal felicidad, por lo tanto, no cumple con el pacto que había sellado con el enterrador y cambia los planes: divide al abuelo entre sus familiares. 
La historia finaliza cuando el protagonista logra solucionar pragmáticamente la ausencia del abuelo y le brinda a su familia complacencia con ello. Desde su propia perspectiva él actuó justamente, pese a haber faltado a su palabra al prometerle al enterrador devolver el cadáver de su abuelo.

Tanto el abordaje temático de la narración como el modo de actuar de sus personajes representan a través de la metáfora una desarticulación o fragmentación del cuerpo (cadáver)/ sujeto muerto, en pos de la búsqueda de una identidad colectiva: la familia. La ausencia del abuelo se homologa al vacío y a la incompletud tanto del protagonista como de la familia. Por ello, sus personajes aceptan -sin el menor reparo- que su abuelo no sólo haya sido exhumado para que asistiera a la reunión familiar, sino también que haya sido cortado con una sierra para que cada quien tuviera un trozo-presencia del abuelo.

Quizás, escuchar el argumento del cuento resulta un tanto descabellado y escalofriante: un hombre desentierra a su abuelo y luego reparte las partes del cuerpo de este entre sus familiares para que ellos no lo extrañen más. Aisladamente, es posible que resulte absurdo, sin embargo, si lo analizamos detenidamente veremos que parte de una premisa constatable: el cuerpo es la representación del sujeto; por eso, el poseer el cuerpo del abuelo se iguala a contar nuevamente con su presencia, a incorporarlo a la sociedad.

Así funciona, nuestros cuerpos nos confieren existencia, "realidad"; pero esto acaba cuando la vida que habita esa masa corpórea se extingue. Pese a que la materialidad del sujeto (cuerpo) no desaparece inmediatamente cuando este fallece, socialmente, sí lo hace. La cultura occidental no admite la mezcla entre el mundo de los vivos y el mundo de los muertos. Todos sus ritos y creencias se inclinan por separarlos y concebirlos como dos "realidades" o "planos" distintos. Por esta razón, el cuento Abuelo opera en contra de la ley y los ritos sagrados asociados a la muerte y el respeto hacia los muertos. El mundo textual trastoca los grandes discursos y las fijadas convenciones.

Y es que más allá de la deslegitimación de los discursos oficiales y el menoscabo de la autoridad, "Abuelo" encierra una redefinición de la muerte y el cuerpo, una desarticulación que describe más realidades que ficciones. Así, la incorporación literal de la muerte (el abuelo) en la vida, constituye, sin duda, un modo figurativo de evidenciar cómo las sociedades centroamericanas contemporáneas conviven con la muerte cada día y cómo el incremento de la violencia transforma inevitablemente la concepción de la muerte y los muertos. Esto explicaría, asimismo, la naturalidad paralizante con la cual actúan los personajes y la inexistencia del mínimo devaneo en sus decisiones, por ejemplo: desenterrar al abuelo, llevar el cadáver a la casa y cortarlo en piezas para compartirlo con su familia.

El tono lacónico con el cual se narra una situación dolorosa: perder a un ser querido, le confiere al texto un sentido más fuerte del que posee en el mundo extratextual. El narrar sucesos angustiosos y sorprendentes como si fueran cotidianos, "normales", "comunes" tiñen de hiperrealidad el objeto metaforizado en el texto: el sujeto fragmentado/desgarrado.

Así es, la realidad extratextual centroamericana está inundada de muertos y sus textos también lo están. Esta realidad desmedida corroe la integridad, la idea de completud, la articulación del sujeto; por ello, el protagonista de "Abuelo" fragmenta el cuerpo de su abuelo, lo disloca; en vez de conservarlo en su casa articulado. El ensamblaje tanto de la familia como del abuelo solo se realizará cuando todos los miembros de la familia se reúnan, antes no.

Ahora bien, la violencia y el desgarramiento de los cuerpos-sujetos se distienden por el resto De fronteras, pareciera que se trata de la columna vertebral que sostiene el 
entrerramado textual. Mas, quizás, uno de los textos más desgarradores es "Manual del hijo muerto. Cuando el hijo está en forma de trozos". En este caso, los lectores se enfrentan ante un cuento conformado por siete párrafos, donde se desarrollan las recomendaciones básicas que debe tomar en cuenta un padre o una madre al reconstruir el cadáver de un hijo, antes de presentarlo o mostrarlo a sus familiares y amigos en la vela. Las instrucciones se refieren al modo en cómo se deben coser las diferentes partes del cuerpo, al lugar ideal para realizar este procedimiento, el tipo de ropa con la cual se debe vestir al cadáver y el maquillaje que se le debe colocar. Sumado a esto, el cuento inserta dos recuadros que contienen una llamada de atención o advertencia (como si se tratara de un producto) y un tip (como si se tratara de una receta culinaria que aparece en una revista). También, incluye una nota al pie donde menciona que el cuento adjunta en el Apéndice B un esquema básico del cuerpo humano, en caso de que alguna persona, debido al dolor que está padeciendo, no pueda reconstruir el cuerpo del hijo; o bien, porque el cuerpo presenta lesiones físicas que deformaron su estado original.

ATENCIÓN ${ }^{9}$ : Atender estas medidas de precaución puede evitarle un desgaste innecesario en el caso de que le hayan entregado los pedazos de un hijo equivocado. Asegúrese, también, de no firmar de recibido antes de estar completamente seguro (a) de que el contenido del paquete le pertenece en su totalidad. Recuerde que no se aceptan devoluciones. (Hernández 2007: 107)

TIP: Extender el cuerpo sobre la cama en la posición de decúbito dorsal, con una pierna flexionada y sin arrugas en la ropa produce siempre la sensación de tener nuevamente en casa no solo a un hijo perfecto, sino a uno vivo. (Hernández 2007: 108)

Tal y como lo evidencian las citas textuales, el tono de la narración no es, en ningún momento, funesto. No presenta conmiseración alguna por quienes atraviesan por una situación como esa; por el contrario, la voz del narrador es directa, simple, concreta. El texto se asemeja a un folletín que acompaña un nuevo electrodoméstico que debe ser armado para que funcione; o bien, a una guía para cultivar una semilla en la tierra. Nuevamente, acá el lector -como en "Abuelo"- podría sentir dañada su sensibilidad, pues se alude a un hecho nefasto desde una actitud impasible.

\footnotetext{
Causa especial emoción reconstruir el cuerpo del niño (24-25 años) que salió completo de la casa hace dos o seis días. Por tal razón, se recomienda tener a mano una caja de pañuelos desechables y no fumar durante el proceso, a fin de evitar humedecer o dañar con fuego o cenizas las delicadas piezas. Antes de iniciar la labor, se sugiere además cerciorarse de que cada una de las partes que le han sido entregadas se corresponda con las señas particulares de su hijo y ensamblen armoniosamente. Con frecuencia, el reconocimiento puede realizarse a simple vista, pero no está de más comparar la dentadura del cadáver con las placas registradas en el archivo del dentista de la familia. (Hernández 2007: 107)
}

Precisamente, la naturaleza flemática del texto en sí provoca una sensación aterradora en el lector. El distanciamiento del narrador de la acción contada causa un efecto opuesto en el lector, ya que termina por colocar a este último en el epicentro mismo de la acción. El lector puede verse a sí mismo uniendo las piezas de un 'supuesto' hijo muerto y esto podría provocarle furia, molestia o repulsión al saber que alguien podría atreverse a brindarle consejos de cómo enfrentar esto.

Sin duda alguna, el tratamiento imperturbable de la muerte y el manejo del cuerpo muerto forman parte de una redefinición de la realidad. En este cuento "Manual del hijo muerto...", la ficción se vuelca sobre la realidad y nos lanza una mirada sobre nosotros 
mismos como sociedad. La ficción se empapa de realidad, destila violencia, muerte, sujetos fragmentados, indiferencia. El texto nos revela un cuerpo desgarrado y con él una textualidad/ realidad desgarradora. Resulta tan común que una familia reciba los trozos del cuerpo de su hijo asesinado que esto se metaforiza en la literatura en la existencia de un manual, de un instructivo para articular sus piezas.

Observamos, con claridad, como se contraponen las búsquedas de "Abuelo" y "Manual del hijo muerto". Mientras uno persigue traer de regreso al abuelo y repartir sus partes; el otro pretende reunir los pedazos de cuerpo dispersos y lacerados para presentarlo a la familia. Mas, ambos coinciden en presentar un sujeto-cuerpo desgarrado por su propia realidad, por su condición social, por su imposibilidad de completud.

Quizás la realidad pesa tanto como duele que es mejor exagerarla, llevarla a su máximo esplendor, vivirla en extremo al menos en el instante de escritura/lectura, no perecer en ella.

\footnotetext{
La muerte violenta es omnipresente, la violencia parece ser imparable y se ha vuelto parte integral de la cotidianidad. Ni siquiera se cuestionan las razones y la procedencia de la violencia. La presencia ubicua de la muerte violenta no se niega pero tampoco lleva a la paralización. Se trata de sobrevivir, de saber manejarse de alguna forma en esa realidad. Los personajes no se dan por vencidos y combaten la violencia aunque sea con fines violentos. [...] Aquí la violencia no se reprime, pero tampoco se logra vencer; nos encontramos en el epicentro mismo de la violencia. (Hass s.f.)
}

Como vemos en "Abuelo" y "Manual del hijo muerto" no se trata de luchar contra la muerte, de combatir la violencia, de castigar a quien la propicie, no. La violencia constituye un modo de vida, ya no se problematiza, no se la ataca con ayuda de los gobiernos o las autoridades. Cada quien, de manera individual, la enfrenta con sus propios métodos, con sus propios valores. Probablemente, nos acostumbramos demasiado a ella y ahora convive con nosotros.

A lo anterior convendría agregar que la violencia -muchas veces- no solo convive con nosotros, sino que también habita, pervive y actúa en contra de nosotros mismos. Justamente, así lo presenta otro cuento de Claudia Hernández en De fronteras titulado "Mediodía de frontera", el cual apunta hacia la violencia auto-infligida. En este caso, el relato se centra en la historia de un perro que entra a un baño público de mujeres, en la frontera, justo al medio día, allí encuentra a una mujer que acaba de arrancarse la lengua y quien le pide que presencie su suicidio, pues los que se ahorcan siempre están solos y ella no quiere estar sola.

Este texto, al igual que los dos cuentos analizados antes, mantiene un tono circunspecto, por ello, no describe con detalle las emociones o los pensamientos de sus personajes, tampoco se detiene a desarrollar - mucho menos a cuestionar- por qué la protagonista ha decidido suicidarse. Las razones se ignoran y parecen no ser relevantes, la decisión ya está tomada y no hay marcha atrás. No obstante, sí se explica el motivo por el cual la mujer decide cortarse la lengua antes de acabar con su vida.

[Ante la presencia del perro en el baño] ella le pide que regrese, que no se vaya, que no la deje. El perro accede ante los ojos temblorosos de ella. Le acerca con la pata un trapo para que se cubra la boca y le pregunta por cortesía qué sucedió y quién pudo hacerle eso. Ella, que sabe que él conoce las respuestas, no responde quién, sino por qué: porque los ahorcados no se ven mal porque cuelguen del techo, sino porque la lengua cuelga de ellos. Es la lengua lo que causa horror. La lengua es lo que provoca lástima. No el cuello. Sólo el forense le presta atención al cuello. La gente común y corriente mira la lengua. Aunque se fija también un poco en los zapatos, es por la lengua que se estremece. Y ella no quiere horrorizar a nadie. Solo quiere ahorcarse. (Hernández 2007: 101-102)

Si bien, el perro accede a quedarse con la mujer hasta que deje de respirar, él no desea saber por qué ella va a quitarse la vida. No intenta disuadirla, no quiere interferir en sus planes 
y luego resultar el responsable de que ella lleve una vida de desgracia. De hecho, "le pide que no le dé a conocer las razones, así, si lo interroga la policía, dirá lo que sabe: nada. Le reserva a ella el derecho de llevarse las explicaciones" (Hernández 2007: 102).

El perro permanece en el baño con la mujer y ella le da su lengua -que aún está calientepara que el perro se la coma. Luego, inicia su ritual de preparación: "se cambia la ropa, se limpia la cara, se sella la boca con pegamento para que, cuando se muera, no pueda verse el hueco sin lengua. Se sella con forma de sonrisa. Quiere ser una ahorcada feliz" (Hernández 2007: 103). Posteriormente, el perro se despide de ella, en un arrebato jura no abandonarla, permanecer allí; luego, ella se cuelga. El perro llora y se queda ahí hasta que unas mujeres descubren el cuerpo y dan aviso a los encargados.

Sin duda alguna, las acciones de este texto son completamente desgarradoras: la automutilación y el suicidio. Empero, si miramos más allá de las acciones en sí podremos rescatar algunos elementos dignos de análisis. En primer lugar, hallaremos la inscripción de la violencia sobre el propio cuerpo, es decir, se trata de una decisión particular, un modo de actuar. Esta mujer decide cómo desea ser percibida por los 'otros' al dejar de respirar (cortarse la lengua, sellarse la boca en forma de sonrisa) y cómo morir (ahorcada). Emplea la violencia contra sí misma para 'irse de este mundo' cuando ella misma lo ha decidido y no cuando alguien más lo decida (sea humano o divino). Su última decisión está fuera de la norma. En realidad, ella desea tener un suicidio atípico, en el sentido de que no desea tener la lengua afuera, razón por la cual se la mutila, y le pide al perro acompañarla, pues ningún suicida muere acompañado. De este modo, trasgrede el sistema y la naturaleza mediante la violencia.

En segundo lugar, debemos rescatar en este texto -como lo hicimos con los otros cuentos- la fragmentación del sujeto. En este caso, la dislocación del cuerpo de la mujer está asociada a los 'otros', a la percepción de quienes la encuentren colgando del techo del baño. Aquí la desarticulación del personaje viene con la autocensura, con lo que pueda causar en los 'otros' la impresión visual de su lengua colgando. En ningún momento, se cuestiona la idea del suicidio, en el texto, esto es una realidad inminente.

En tercer lugar, conviene rescatar dónde se desarrolla la acción y qué implicaciones posee esto para el abordaje de este estudio. Tal y como se mencionó antes, la historia cobra lugar en un baño de frontera. Acá debemos subrayar que el espacio del baño es un sitio que se ubica entre la esfera de lo público y lo privado. Es posible que esta mujer quisiera ser descubierta por los 'otros', pero a la vez, no quería ser interrumpida mientras se colgaba, eso quería reservárselo para sí. Vemos aquí como entran en tensión la representación de los espacios que determinan la identidad de los sujetos: el afuera y el adentro. Asimismo, no resulta casualidad que el baño se localice en una frontera. Las fronteras son sitios/líneas imaginarias trazadas geopolíticamente para determinar la pertenencia de los sujetos y los territorios a diversas naciones. Cuando se está en una frontera se está en un lugar inexistente, es decir, esa supuesta barrera que divide un país de otro no existe en realidad; por dicha razón, es un espacio de etiquetas políticas: legal, ilegal, extranjero, nacional, fugitivo. Un lugar que asigna identidades. Un sitio donde imperan -muchas veces- los conflictos, las muertes y las masacres debido a la entrada masiva de inmigrantes ilegales y al tráfico internacional de drogas.

Según lo expuesto, cuando la mujer de "Mediodía de frontera" se suicida en un baño, su propio aniquilamiento en 'el lugar cero' es, de algún modo, su autodefinición. Es el modo que halló este sujeto posmoderno para ser/dejar de ser. Fue un acto realizado a plena luz del día, cuando el sol estaba en el cénit, un acto que dejó en su boca -sin lengua- una sonrisa tan perpetua como la violencia desgarradora de su tiempo. 
Tras la aproximación a la textualidad de Claudia Hernández resulta ineludible percibir cómo los cuerpos que transitan y pueblan los textos centroamericanos sacuden sin piedad nuestras construcciones identitarias y nuestras realidades. Esos cuerpos-sujetos textuales al metaforizarse mediante el desgarramiento, la desritualización, la fragmentación, la mutilación y el aniquilamiento nos ponen en evidencia a cada uno de nosotros, frente a nuestros ojos, en las páginas de nuestros textos. Tal parece que el músculo de la memoria no deja de agitar la producción literaria centroamericana, así lo confirman sus textualidades desgarradoras.

\section{Notas}

1. "Ella está en el horizonte - dice Fernando Birri-. Me acerco dos pasos, ella se aleja dos pasos. Camino diez pasos y el horizonte se corre diez pasos más allá. Por mucho que yo camine, nunca la alcanzaré. ¿Para qué sirve la utopía? Para eso sirve: para caminar”.

2. Licenciada en comunicaciones de la Universidad Tecnológica de El Salvador, realizó también estudios de derecho. En 1998 ganó el primer honorífico (4 lugar) del premio "Juan Rulfo" de Radio Francia Internacional, en la categoría de cuento. En 2004 obtuvo el prestigioso premio "Anna Seghers", en Alemania, por su obra publicada. Sus textos son parte de antologías en España, Italia, Francia, Estados Unidos y Alemania. Actualmente trabaja como catedrática de la Universidad Centroamericana José Simeón Cañas (UCA).

Entre sus obras están: Otras ciudades (2001), Mediodía de frontera (2002), Olvida Uno (2005), De fronteras (2007), La canción del mar (2007). Algunas de las antologías en las cuales han sido publicados sus trabajos son: Los centroamericanos (2002), Pequeñas resistencias 2. Antología del cuento centroamericano contemporáneo (2003), Antología de cuentistas salvadoreñas (2004), Cicatrices. Un retrato del cuento centroamericano (2004).

3. Así lo manifiesta Albizúrez Palma, al asegurar que se trata de un proyecto de carácter centroamericano al generarse a raíz de la interacción de los diferentes escritores del istmo.

4. Cortez hace énfasis en la ruptura de las utopías que caracterizaron las generaciones de escritores más reconocidas en el país, desde la "Generación del 44" que se vio involucrada en el derrocamiento de Maximiliano Hernández Martínez hasta la "Generación Comprometida” surgida en el conflicto bélico salvadoreño.

5. Beatriz Cortez se refiere a la relación existente entre el testimonio centroamericano y las estructuras de poder. Siguiendo los estudios de Michel Foucault, Cortez propone que el manejo del poder estará determinado por el acceso al discurso, por tanto la verdad no podrá existir al margen del poder, sólo puede nacer de él. En este sentido, la producción testimonial desestabilizará la oficialidad, mas no significará incorporar a la subalternidad pues, ésta "no puede hablar como tal, pues al hacerlo deja de ser subalternidad para convertirse en representación” (Cortez 2001: 3).

Si bien, el testimonio propone una construcción alternativa de la historia no representa 'la' verdad ya que siempre estará de por medio la ideología de quien decide re-escribir el pasado. Finalmente, la construcción de los sujetos "se presenta entonces como un espacio donde se reproducen las jerarquías de poder generadas por el sistema imperante" (Cortez: 2001: 8).

6. Este escritor salvadoreño duda de la existencia de una generación de escritores en el sentido clásico de la denominación, pues sostiene que no mantiene una relación literaria con ninguno de los escritores incluidos en la "generación del cinismo". Agrega que dichas denominaciones son guías requeridas por los académicos para encasillar las obras de tal manera que se encuentren líneas comunes. Para Castellanos Moya esto se resume en la percepción de que un grupo de obras literarias expresan un periodo político de la historia salvadoreña, en el cual las ilusiones de la guerra y de la revolución de que El Salvador se iba a convertir en una sociedad socialista revolucionaria no se vieron cumplidas. Sumado a lo anterior, el escritor apunta que uno de los motivos por los que la sociedad vio desvanecerse esas utopías es porque en El Salvador la salida de la guerra fue con base a la negociación y no se dio un sentimiento de épica, de un ganador y un derrotado como en Nicaragua o Cuba. 
7. Conviene señalar que esta lista de autores resulta excluyente, por ello, quisiera que funcionara como un ejemplo de la ubicación realizada por la historiografía y no como una especie de encasillamiento apoyado por esta investigación. Por tanto, otros listados podrán resultar, eventualmente, tan válidos o discordantes como este.

8. "El Salvador actualmente es uno de los países más peligrosos del mundo donde a diario son asesinadas unas 11 personas, y esto se ve con ojos de cotidianidad, la violencia y la muerte son el pan de cada día de los salvadoreños, la sociedad salvadoreña se ha vuelto cínica” (Sánchez 2011).

9. Las siguientes citas textuales se trascriben en forma de cuadro dado que así se presenta en el texto. De igual modo, la negrita pertenece al texto original.

\section{Bibliografía}

Albizúrez, Francisco. 1995. Poesía contemporánea de la América Central. San José: Editorial Costa Rica.

Barbero, Jesús Martín. 2003. "Los laberintos urbanos del miedo". Universitas Humanística. 30 (56): 69-79.

Cortez, Beatriz. 2000. Estética del cinismo: la ficción centroamericana de posguerra. V Congreso Centroamericano de Historia, Universidad de El Salvador, 19-21 de julio del 2000. http://www.ues.edu.sv/congreso/Cortez,\%20literatura.pdf

2001. La verdad y otras ficciones: visiones críticas sobre el testimonio centroamericano. Istmo. Revista virtual de estudios literarios y culturales centroamericanos. 2. http:// www.denison.edu/collaborations/stmo/v01n02/articulos/testim.html

Eagleton, Terry. 1997. Las ilusiones del posmodernismo. Buenos Aires: Paidós.

Follari, Roberto. 1994. Modernidad y posmodernidad: una óptica desde América Latina. Argentina: Rei Argentina/Aique Grupo Editor.

Giddens, Anthony. 1995. Modernidad e identidad del yo. El yo y la sociedad en la época contemporánea. Barcelona: Península.

Haas, Nadine. s.f.. "Claudia Hernández y lo surreal de la violencia”. Revista Luna Park. 31. http://www.revistalunapark.com/index.php?option=com_content\&view=article\&id=7 $1 \&$ Itemid=331

Heller, Agnes. 1996. Una revisión de la teoría de las necesidades. Barcelona: Paidós.

Hernández, Claudia. 2007. De fronteras. Guatemala: Piedra Santa.

Sánchez, Hugo. 2011. “Generación del cinismo y la desesperanza”. Diario digital Contrapunto. El Salvador. http://www.contrapunto.com.sv/cparchivo/pensamiento/generacion-delcinismo-y-desesperanza

Torras, Meri. 2007. El delito del cuerpo. Cuerpo e identidad. Barcelona: UAB.

Torres-Rivas, Edelberto (Ed.). 1994. Historia general de Centroamérica. Historia inmediata (1979-1991). Tomo VI. San José: FLACSO.

Vásquez, Magdalena et al. 2002. "Nueva narrativa venezolana: el desencanto ante la realidad en la novela Calletania”. Káñina, Revista de Artes y Letras. 26 (1): 25-37. 